\title{
doi.org/10.46291/ISPECIJSSHvol4iss4pp343-349
}

\section{Impact of Counselling on Mental Health and Academic Anxiety: A Review of Existing Literature}

\section{Tabassum Fatima \\ Kashifa Khan}

Dr., Department of Education, Aligarh Muslim University, Aligarh, Uttar Pradesh, INDIA, tabi.ftm@gmail.com

Dr., Department of Education, Regional Institute of Education, Ajmer, Rajasthan, INDIA, kashifakhan1990@gmail.com

\begin{abstract}
Adolescence is crucial period in the life span where there are notable opportunities for the changing life experiences, there is lack of counselling services for mental health, anxiety and well-being. Mental health is now recognised is being crucial to over-all health and it is defined as 'subjective wellbeing, perceived self-efficacy, autonomy, competence, intergenerational dependence and self-actualization of adolescence. Despite widespread and increasing awareness of the mental health, anxiety and other psycho-social challenges which are being faced by adolescents, their needs in this area are largely unmet particularly in India. Counselling services can be contributed in adolescent's mental health, academic anxiety, other psycho-social aspects for their successful completion of educational process and further entries in the various work-fields and employment. Counselling can play crucial role in achieving the dual goals of school safety and educational improvement, supportive and positive learning environment for them. Thus, the present study is an attempt to review the impact of counselling services on mental health and academic anxiety among adolescents, based on review of previous researches that have been conducted. The discussion along with some suggested measures have been included in research paper for emphasising the impacts of counselling for adequate mental health and academic anxiety.
\end{abstract}

Keywords: Counselling, Mental-health, Academic anxiety.

\section{Introduction:}

Adolescence is a crucial period in the life span of individual where there are notable opportunities for the changing life experiences. They are the backbone of the nation their allround development is very much required in life specially in the present face which created several challenges in their life. The stage of adolescence is located between childhood and 
adulthood when the child is neither very young nor very old. However, definitions differ, the United Nations defines adolescence as the second decade of life between 10 and 19 years (UNICEF,2011). Mental ill health and psycho-social problems typically starts during adolescence, unless young girls and boys receive appropriate treatment, of these psycho-social problems will continue to affect them as adults (WHO,2007). Mental health is now recognised is being crucial to over-all health (e. g. WHO,2014) and is defined as including, subjective wellbeing, perceived self-efficacy, autonomy, competence, intergenerational dependence and self-actualization of one's intellectual and emotional potential among others (WHO,2001). A study noted that between 10 to 20 percent of children and young people have been reported as experiencing diagnosable mental illness (Kieling et al.2011).This is leading to rising suicide rates with young people now the highest risk group for suicide in around 30\% of all countries (WHO,2007,2016). In china, India and the South East Asia region, suicide is the leading cause of death among those aged 15 to 19 (Patel et al.2007; WHO,2014). Despite widespread and increasing awareness of the mental health, anxiety, aspirations and other psycho-social challenges which are being faced by adolescents, their needs in this area are largely unmet particularly in developing countries like India. The continuous pressure from outside world over the abilities and various aspects of human behaviour causes restless in the mind of the adolescents. One among them is academic anxiety, academic anxiety is feeling of being distressed, fearful, or stressed out as a result of school pressures. The anxiety that occurs in post- traumatic syndromes indicates that human memory is much more complicated mental function than animal memory. All the responsibilities of being an academic brings with it a state of mind referred to as "academic anxiety. Developing a state of academic anxiety causes a decrease in attention span, concentration and memory which can result in having a negative effect on the performance of the individual. The term counselling broadly refers to the process of meeting the needs of students in the several areas or development, such as academic, carrier and personal. Expert agree that counselling programs should be comprehensive in scope, preventative in design and developmental in nature. Counsellors can also identify students who need extra assistance and attention from watching them interact with their peers in classroom selling. Counselling can play a crucial role in achieving the dual goals of school safety and educational improvement, supportive and positive learning environment for all. Hence, it is essential to review the Impact of Counselling on Mental 
Health and Academic Anxiety so that role of counselling could be defined and taken to each adolescent in every nook and corner of the country.

Objectives of the Study: The main objectives of this research paper aere: -

1. To analyse the relevance of counselling services for mental health and academic anxiety for adolescents.

2. To analyse the impact of counselling on adolescent's mental health and academic anxiety.

3. To identify and give suggestions in obstacles for counselling services for adolescents.

\section{Research Methodology:}

This research paper is descriptive and analytical in nature based on existing literature. In this paper attempt has been taken to realize the relevance and impact of various counselling programmes on mental health and academic anxiety among adolescents in India. The data for the study is purely from secondary sources according to the necessity of the paper.

\section{Review of Literature:}

In research on counselling services conducted by researchers' large number of studies have examined relationship between mental health and academic achievement of adolescents. Almost all reported positive relation or influence of mental health on academic anxiety.

Samuels, F. et al (2017) carried out a study on psychosocial support for adolescent girls in post-conflict settings: beyond a health system approach. The study focuses on the importance of psychosocial support services for adolescent girls in fragile context. Sivagurunathan et al (2015) in their review article on Adolescent Health: Present Status and Its Related Programmes in India intend to create awareness among the stakeholders about the importance of strengthening adolescent health services in order to meet their felt needs. Universal coverage of Adolescent friendly clinics is highly recommended. They concluded in their study intended to create awareness among the stakeholders in India about the importance of strengthening adolescent health services in order to meet their felt needs through the concept

Year 4/ 2020, Volume-4, Issue-4 | WWW.ispecjournal.org 
of adolescent's friendly clinics. Pushpalatha, C \& Sasikala, S. (2015) found in their study, Counselling needs among adolescent students. Study revealed that, unfortunately most of the schools do not have proper counselling facilities. Vijyalaxmi, C. and Varsha, J. (2014) investigated the Counseling Needs of adolescents. A sample of 120 respondents was selected. The Psychological Counseling Need Scale (PCNS) was used. Data were analyzed using t test. It was found that there is no significant difference between the response of male and female adolescents. Janetis S.T. (2012) In his study focused on the major concerns and constrains of college students that need counselling assistance and developed a comprehensive counselling program in the Indian higher education scenario. Findings showed that a great number of students are having some major issues that obstruct their focus on studies. Mihai and Mihaela (2011) studied longitudinal study regarding the psychologist profession and the vocational guidance of Romanian high school students. The research highlights the need for promoting the academic specializations and career development in psychology beginning with the 10th grade by qualified persons such as the educational counsellors. Azmitia, et al. (2009) examined support and guidance from families, friends, and teachers in Latino early adolescents' youth reported that parents and siblings provided the most support and guidance across these years, followed by friends, and to a lesser extent, teachers, who primarily helped with homework. However, only families' support, guidance, and income predicted math grades. Implications for research, policy, and practice highlight immigrant Latino families with modest schooling as resources and how Latino youth draw resources from families, friends, and schools. Michiko (2005) has examined the mental health and counselling in Japan: A path toward societal transformation. This article underscores the importance of mental health counsellors working congruently within Japanese society by incorporating the social justice perspective. Emphasis is placed on culturally specific trends and resources in order to prevent conflicts and to maintain harmony among individuals within the changing societal systems. Razmi (1999), Baum \& Fleming (1993), Khodaei (1997) in their researches have shown the effectiveness of counselling in decreasing the academic anxiety of students. Arulmani, G. (2007) noted in a survey he conducted in 1993 that only 5 percent of school principals believed counselling in schools was important. However, in 2000 for the same survey, 95 percent of school heads agreed that school counselling was not only important but is an urgently required service. Studies have showed that mental health is a distant concept for parents and duties of counsellor are still vague and undefined. Venkatesan 
and Shyam (2015) conducted an exploratory cross-sectional study in the state of Karnataka, India and revealed that school counsellors wanted to focus on the students' problems and issues but parents and teachers were keener on academic advising, student discipline, conflict resolution, crisis interventions etc. School administer were expecting school counsellors to help them in admissions and staff development showing a disparity in perception of school counsellor's role and responsibility.

\section{Conclusions and Suggestions:}

Adolescence is a period of span of growth and development with new exposures in life. It has become necessary now to keep a track of the mental health and academic anxiety. Counselling services supports mental health, academic anxiety and other psycho-social aspects for their successful completion of educational process and further entries in the various work-fields. After going through some specific and current studies which have been undertaken in last decade it may be concluded that there is dire need of various guidance and counselling programmes for adolescent's mental health, academic anxiety and other psychosocial wellbeing specially in Indian context. Adolescents are developing socially, mentally, physically and emotionally which includes lots of mental pressure due to parental aspiration, society recognition and to perform effectively in various competitive exams which may get them a bright settled future in society. With new exposures in life it has become necessary now to keep a track of the mental health of an adolescent as only healthy mind is able to withstand the competition and perform upto the capabilities. In 2001, the Central Board of Secondary Education (CBSE), one of the largest education boards in India made it mandatory to have a trained school counsellor in all their schools. They also started telephone counselling in various cities to provide help for students during examination time. The National Council of Educational Research and Training (NCERT, 2005), also recognized that guidance and counselling be made available in schools to deal with stress related problems and incorporate teachers and parents to lessen stress. They also emphasized on the teachers with a background in guidance and counselling to students in achieving educational, developmental and emotional needs and assisting them to prepare for future vocational life. The pressure has been increased many folds on the adolescents regarding the professional career due to the global recession a likely consequence of the COVID-19 pandemic. To deal with it they have started telephonic counselling services for students to deal with the anxiety 
and pressure. This should be made compulsory to be followed by all the boards including state boards.

\section{References:}

Arulmani, G. (2007). Counselling Psychology in India: At the Confluence of Two Traditions. International association of applied psychology. 56 (1).

Azmita, M., Catheribe, R. C. \& Brown, J. R. (2009). Support and Guidance from Families, Friends, and Teachers in Latino Early Adolescents' Math Pathways. Sage Journasl; The journal of early adolescence, 29 (1).

Baum, A. and Fleming, I. (1993). Implications of psychological research on stress and technological accidents. Amer. Psychol., 48(6): 665-672.

Chauhan, V. \& Joshi, V. (2014). Sex difference in counselling needs: A study among adolescents. Indian Journal of Psychology and education, 4 (1).

Hajloo, N. (2011). The Study of Counselling Services Effect on Iranian Adolescence's Mental Health. Elsevier; Procedia-Social and behavioural sciences. 30(2011).

Janetis S.T. (2012) Indigenous therapeutic counselling in the Indian context Conference Paper. 2nd Asia Pacific Rim International Counselling Conference 6th to 8th July 2011 Dept. of Counselling \& Psychology, HK Shue Yan University, 10 Wai Tsui Crescent, Braemar Hill, North Point, Hong Kong, At Hong Kong.

Khodaei, K.S. (1997). The effect of group counselling approach with emphasis on reducing anxiety in connection dialog Mshkynshahr high school students. [research project]. Ardebil: Education Research Council. [Persian]

Kieling C., Baker-Henningham H., Belfer M., et al (2011). Child and adolescent mental health worldwide: evidence for action. The Lancet 378: 1515-25.

Mihai, A. \& Mihaela, C. (2011). A longitudinal study regarding the psychologist profession and the vocational guidance of Romanian high school students. Procedia - Social and Behavioural Sciences 29:1677-1682.

Michiko, I. (2005). Mental Health and Counselling in Japan: A Path Toward Societal Transformation. Journal of Mental Health Counselling. 27 (2).

Year 4/ 2020, Volume-4, Issue-4 | WWW.ispecjournal.org 
Patel V., Flisher AJ., Hetrick S., McGorry P. (2007). Mental health of young people: a global public-health challenge, The Lancet 369: 1302-13.

Pushpalatha, C. \& Sasaikala. S. (2015). Counselling needs among adolescent students. Indian Journal of Applied Research. 5 (12). ISSN-2249-555X.

Razmi, A. (1999). Success factors in Ardebil province consultants [research project]. Ardebil: Education Research Council. [Persian]

Samuels, F., Jones, N. and Bassam, A. H. (2017). Psychosocial support for adolescent girls in post-conflict settings: beyond a health systems approach. Oxford Journals; Health policy and Planning 2017 Dec; 32(Suppl 5): v40-v51.

Shivgrunathan et al (2015) Adolescent Health: Present Status and its related programmes in India. Are we in the right direction? Journal of clinical and diagnostic Research: JCDR. 9 (3) LE01. 2015.

UNICEF (2011). The state of the world's children 2011. Adolescence: An age of opportunity. New York: United Nations Children's Fund.

Venkatesan, S., \& Shyam, H.R. (2015).Professional Identity of School Counselors in India. Journal of Indian Academy of Applied Psychology, 41, 1, 25-36.

Vijyalaxmi, C \& Varsha, J. (2014). Sex Difference in Counseling Needs: A Study Among Adolescents, Indian Journal of Psychology and Education, Vol.4, No.1, 40-42.

WHO (2001) The World Report 2001, Mental Health: New Understanding, New Hope. Geneva: World Health Organization.

WHO (2007) Helping Youth Overcome Mental Health Problems. Geneva World Health Organization.

WHO (2014) Health for the world's adolescents. A second chance in the second date. Geneva World Health Organization.

WHO (2016) Preventing Suicide: A global imperative. Switzerland. http://apps.who.int/iris/bitsteam/10665/131056/1/9789241564779_eng.pdf?ua=1\&ua= $\underline{1}$

Year 4/ 2020, Volume-4, Issue-4 | WWW.ispecjournal.org 